\title{
Conjugated Linoleic Acid Production by Bifidobacteria: Screening, Kinetic, and Composition
}

\author{
Stefano Raimondi, Alberto Amaretti, Alan Leonardi, Andrea Quartieri, \\ Caterina Gozzoli, and Maddalena Rossi \\ Department of Life Sciences, University of Modena and Reggio Emilia, Via Campi 103, 41125 Modena, Italy \\ Correspondence should be addressed to Stefano Raimondi; stefano.raimondi@unimore.it
}

Received 18 March 2016; Accepted 29 May 2016

Academic Editor: Ibrahim M. Banat

Copyright (C) 2016 Stefano Raimondi et al. This is an open access article distributed under the Creative Commons Attribution License, which permits unrestricted use, distribution, and reproduction in any medium, provided the original work is properly cited.

\begin{abstract}
Conjugated linoleic acids (CLA) are positional and geometric isomers of linoleic acid involved in a number of health aspects. In humans, CLA production is performed by gut microbiota, including some species of potential probiotic bifidobacteria. 128 strains of 31 Bifidobacterium species were screened with a spectrophotometric assay to identify novel CLA producers. Most species were nonproducers, while producers belonged to B. breve and B. pseudocatenulatum. GC-MS revealed that CLA producer strains yielded 9cis,11trans-CLA and 9trans,11trans-CLA, without any production of other isomers. Hydroxylated forms of LA were absent in producer strains, suggesting that the myosin-cross-reactive antigen (MCRA) protein that exerts hydratase activity is not involved in LA isomerization. Moreover, both CLA producer and nonproducer species bear a MCRA homologue. The strain B. breve WC 0421 was the best CLA producer, converting LA into 68.8\% 9cis,11trans-CLA and 25.1\% 9trans,11trans-CLA. Production occurred mostly during the lag and the exponential phase. For the first time, production and incorporation of CLA in biomass were assessed. B. breve WC 0421 stored CLA in the form of free fatty acids, without changing the composition of the esterified fatty acids, which mainly occurred in the plasmatic membrane.
\end{abstract}

\section{Introduction}

Conjugated linoleic acids (CLA) are a group of positional and geometric isomers of linoleic acid (LA, cis9, cis12-C18:2) that have conjugated double bonds. Diverse CLA isomers have been identified with different position (ranging from $\Delta 7, \Delta 9$ to $\Delta 12, \Delta 14)$ and cis/trans geometry. 9 cis,11trans-CLA and 10trans,12cis-CLA are the major isomers occurring in human diet, the former being contained mostly in ruminant meat and dairy products and the latter in hydrogenated oils. Considerable research has been directed toward understanding the production and the physiological effects of CLA and there is increasing evidence of their involvement in a number of health aspects. Potential health-promoting properties of CLA include anticarcinogenesis, antiatherosclerosis, antidiabetes, antiobesity, antiallergy activities, and enhancement of immune functions [1].

CLA are intermediates of the biohydrogenation of linoleic acid (LA) and unsaturated fatty acids, a microbial process by which the fatty acids released by lipolytic enzymes undergo the progressive saturation. Microbial isomerization of LA into CLA was firstly described in the gut of ruminants, but diverse isolates from human feces have been demonstrated to take part in LA biohydrogenation, indicating that production of CLA and 11trans-C18:1 (vaccenic acid) occurs in the human gut as well [2-5]. In fact, humans excrete some linoleic acid (LA) with feces [6], suggesting that this substrate is available for microbial production of CLA within the colon. Several colonic species belonging to Cluster IV, Cluster XIVa, and Bifidobacterium genus are involved in LA transformation toward CLA, including 9cis,11trans-CLA and vaccenic acid.

Some species of bifidobacteria, natural colonizers of the gut, are capable to transform LA into 9cis,11trans-CLA and into lower amounts of 9 trans,11trans-CLA and 10trans,12cisCLA. Previous studies suggested that the MCRA protein of bifidobacteria may be involved in isomerization of LA to CLA, through hydration of unsaturated fatty acids, for example, converting palmitoleic, oleic, and linoleic acids to 
the corresponding 10-hydroxy fatty acids [7, 8]. However, more recent evidences excluded the role of bifidobacterial MCRA in CLA production [9].

The ability of various bifidobacteria to produce 9cis,11trans-CLA raised the question as to whether CLA production may be regarded as one of the mechanisms by which bifidobacteria exert some of their beneficial properties [10]. In fact, it is known that commensal bifidobacteria exert a number of beneficial health effects through a variety of different mechanisms.

For this reason, they are increasingly being used in functional foods and pharmaceutical products and are generally regarded as probiotics [11-13]. The present study aimed to identify novel CLA producers among a wide range of Bifidobacterium species and strains and to explore unedited aspects of CLA accumulation, such as the effect of LA and CLA in microbial lipid composition and the accumulation of hydroxylated forms of linoleic acid, ascribable to MCRA activity.

\section{Materials and Methods}

2.1. Chemicals, Strains, and Culture Conditions. All chemicals were purchased from Sigma Aldrich (Steinheim Germany) unless otherwise stated. 128 strains of Bifidobacterium (Table 1) were obtained from ATCC or from our culture collection (WC-labeled strains). Bifidobacteria were cultured in lactobacilli deMan-Rogosa-Sharpe broth (Becton Dickinson, Franklin Lakes, NJ, USA) supplemented with $0.5 \mathrm{~g} / \mathrm{L} \mathrm{L}$-cysteine $\cdot \mathrm{HCl}$ (hereinafter called MRS), at $37^{\circ} \mathrm{C}$ in an anaerobic cabinet (Forma Scientific, Marietta, OH, USA) under $\mathrm{N}_{2} 85 \%, \mathrm{CO}_{2} 10 \%$, and $\mathrm{H}_{2} 5 \%$ atmosphere.

The analysis of the biotransformation of linoleic acid (LA) into conjugated linoleic acid (CLA) was carried out in MRS broth supplemented with $0.5 \mathrm{~g} / \mathrm{L}$ LA (hereinafter called MRS-LA). A solution of $40 \mathrm{mg} / \mathrm{mL} \mathrm{LA}$ in $20 \mathrm{~g} / \mathrm{L}$ Tween 80 was prepared, filter sterilized (cellulose acetate, $0.22 \mu \mathrm{m}$; Millipore, Billerica, MA, USA), and added to the sterile MRS in proper amount to obtain $0.5 \mathrm{~g} / \mathrm{L}$ LA. Bifidobacteria from $16 \mathrm{~h}$ MRS cultures were inoculated $(10 \% \mathrm{v} / \mathrm{v})$ into MRS-LA and incubated at $37^{\circ} \mathrm{C}$ for $48 \mathrm{~h}$.

\subsection{Kinetic of CLA Production and Bioreactor Operation.} Controlled-pH batch cultures were carried out in laboratoryscale fermenters (Sixfors, Infors, Bottmingen, Switzerland) with $500 \mathrm{~mL}$ of MRS or MRS-LA medium. The bioreactor was inoculated with $50 \mathrm{~mL}$ of a $24 \mathrm{~h}$ seed culture grown in MRS or MRS-LA medium, respectively. To investigate CLA production during stationary phase, LA was added to MRS cultures after $24 \mathrm{~h}$ of growth. Temperature was kept at $37^{\circ} \mathrm{C}$, stirring at $200 \mathrm{rpm}$, and $\mathrm{pH}$ was maintained constant at 5.5 through the automatic addition of $4 \mathrm{M} \mathrm{NaOH}$. The bioreactor was kept under nitrogen overpressure to maintain anaerobiosis conditions. The culture was periodically sampled to monitor bacterial growth, glucose consumption, and the concentration of LA and CLA in the broth. The biomass/substrate yield $\left(Y_{\mathrm{X} / \mathrm{S}}\right)$ was expressed as $\mathrm{g}$ of dry biomass $\mathrm{g}^{-1}$ consumed glucose. During the mid-exponential growth phase and at the entrance of the stationary phase,
TABLE 1: Bifidobacterium strains screened for CLA production, by measuring the absorbance of conjugate diene $\left(A_{233}\right)$ after $24 \mathrm{~h}$ growth in MRS-LA. * indicates species bearing a gene homologue to MCRA from B. breve NCIMB 702258. The 34 strains that were selected for GC quantification of CLA and PCR amplification are underscored.

\begin{tabular}{|c|c|}
\hline Species & Strains \\
\hline B. adolescentis ${ }^{*}$ & ATCC 15703, WC 9806 \\
\hline B. angulatum ${ }^{*}$ & ATCC 27535 \\
\hline \multirow{2}{*}{ B. animalis subsp. animalis* } & ATCC 25527, WC 0409, WC 9343 \\
\hline & $\underline{\text { WC } 0410}$ \\
\hline \multirow{4}{*}{ B. animalis subsp. lactis ${ }^{*}$} & ATCC 27536, WC 0411, WC 0412, \\
\hline & WC 0413, WC 0414, WC 0432, \\
\hline & WC 0455, WC 0459, WC 0460, \\
\hline & $\underline{\text { WC } 0469}, \underline{\text { WC } 0471}$ \\
\hline B. asteroides & ATCC 25910 \\
\hline B. bifidum ${ }^{*}$ & WC 0415, WC 0417, WC 0418 \\
\hline B. boum & ATCC 27917 \\
\hline \multirow{8}{*}{ B. breve* } & WC 0420, WC 0421, WC 0422, \\
\hline & $\underline{\text { WC } 0423}$, WC 0424, WC 9436 , \\
\hline & WC 9437, WC 9445, WC 9445, \\
\hline & WC 9446, WC 9449, WC 9491, \\
\hline & WC 9492, WC 9493, WC 9495, \\
\hline & WC 9498, WC 9499, WC 9500, \\
\hline & WC 9501, WC 9504, WC 9505, \\
\hline & WC 9508 \\
\hline B. catenulatum ${ }^{*}$ & ATCC 27539, WC $0458, \underline{\text { WC } 0467}$ \\
\hline B. choerinum & ATCC 27686 \\
\hline B. coryneforme & ATCC 25911 \\
\hline B. cuniculi & ATCC 27916 \\
\hline B. dentium ${ }^{*}$ & ATCC 27534 \\
\hline B. gallicum & ATCC 49850 \\
\hline B. gallinarum & ATCC 33777 \\
\hline B. indicum & ATCC 25912 \\
\hline \multirow{9}{*}{ B. longum subsp. infantis ${ }^{*}$} & ATCC 15697, WC 0433, \\
\hline & WC 0434 \\
\hline & ATCC 15707, WC 0435, WC 0436, \\
\hline & WC 0437, WC 0438, WC 0439, \\
\hline & WC 0440, WC 0441, WC 0442, \\
\hline & $\underline{\text { WC } 0443}$, WC $0444, \underline{\text { WC } 0473}$ \\
\hline & WC 9711, WC 9712, WC 9717, \\
\hline & WC 9718, WC 9721, WC 9722, \\
\hline & WC 9724, WC 9741, WC 9742, \\
\hline \multirow{8}{*}{ B. longum subsp. longum ${ }^{*}$} & WC 9743, WC 9745, WC 9746, \\
\hline & WC 9747, WC 9748, WC 9749, \\
\hline & WC 9751, WC 9752, WC 9753, \\
\hline & WC 9754, WC 9756, WC 9757, \\
\hline & WC 9758, WC 9759, WC 9760, \\
\hline & WC 9761, WC 9762, WC 9763, \\
\hline & WC 9765, WC 9766, WC 9767, \\
\hline & WC 9768, WC 9769, WC 9770, \\
\hline
\end{tabular}


TABle 1: Continued.

\begin{tabular}{lc}
\hline Species & Strains \\
\hline & WC 9772, WC 9773 \\
B. longum subsp. suis & ATCC 27533 \\
B. magnum & ATCC 27540 \\
B. merycicum & ATCC 49391 \\
B. minimum & ATCC 27538 \\
B. pullorum & ATCC 27685 \\
& ATCC 27919, WC 0400, WC 0401, \\
B. pseudocatenulatum & WC 0402, WC 0403, WC 0404, \\
& WC 0405, WC 0407, WC 0408, \\
B. pseudolongum & WC 9359 \\
B. psychraerophilum & ATCC 25526 \\
B. ruminantium & NCIMB 13940 \\
B. saeculare & ATCC 49390 \\
B. scardovii & ATCC 49392 \\
B. subtile & ATCC BAA-773 \\
B. thermophilum & ATCC 27683 \\
\hline
\end{tabular}

$200 \mathrm{~mL}$ of the culture were collected in order to separate the biomass and perform on it the analysis of lipid fraction.

2.3. Spectrophotometric Analysis of CLA in the Supernatant. In order to screen all the bifidobacteria for the capability to produce CLA, a rapid spectrophotometric method was used, based on UV absorption of conjugated double bonds [14]. The culture sample was centrifuged $\left(13,000 \times \mathrm{g}\right.$ for $5 \mathrm{~min}$ at $\left.4^{\circ} \mathrm{C}\right)$ and $1 \mathrm{~mL}$ of supernatant was mixed with $2 \mathrm{~mL}$ of isopropanol. After the addition of $1.5 \mathrm{~mL}$ of hexane, the sample was thoroughly vortexed in order to extract the lipids and then allowed to stand $5 \mathrm{~min}$. The hexane layer was collected and the absorbance was measured at $233 \mathrm{~nm}\left(A_{233}\right)$.

2.4. Extraction of Lipids and Preparation of Fatty Acyl-MethylEsters. To extract cell-associated lipids, the biomass of $200 \mathrm{~mL}$ of culture was harvested by centrifugation $(9,000 \times \mathrm{g}$ for $10 \mathrm{~min}$ at $4^{\circ} \mathrm{C}$ ), washed with water, frozen at $-80^{\circ} \mathrm{C}$, and lyophilized (Heto Lyolab 3000, Allerød, Denmark). Lyophilized biomass was mixed $(2 \% \mathrm{w} / \mathrm{v})$ with a $2: 1(\mathrm{v} / \mathrm{v})$ chloroform : methanol solution and shaken at r.t. for $16 \mathrm{~h}$. The extract was filtered through celite and anhydrous $\mathrm{Na}_{2} \mathrm{SO}_{4}$, solvents were removed using a rotavapor apparatus, and lipids were weighed. To determine the amount of LA and CLA in the supernatant, $3 \mathrm{~mL}$ was thoroughly vortexed with $3 \mathrm{~mL}$ of ethyl acetate. The organic phase was separated and anhydrified; then the solvent was removed.

The free fatty acids (FFAs) and the esterified fatty acids (EFAs), such as glycerides and phospholipids, were transformed into the corresponding methyl-esters (FAMEs) to be analyzed by GC-MS. The FFAs contained in the lipid extract of the biomass or the supernatant were methylated through diazomethane reaction [15]. The extract was dissolved in the ethyl ether solution of diazomethane, freshly prepared from Diazald, and incubated at r.t. for $10 \mathrm{~min}$. Once the solvent had evaporated, FAMEs were dissolved in $1 \mathrm{~mL}$ of ethyl acetate containing $0.5 \mathrm{mg} / \mathrm{mL}$ methyl undecanoate as internal standard and analyzed.

The EFAs contained in the lipid extract of the biomass were transesterified through alkali-catalyzed reaction [16]. The lipid extract was dissolved in $2 \mathrm{~mL}$ of ethyl ether containing $1 \mathrm{mg} / \mathrm{mL}$ triundecanoin as internal standard. $50 \mu \mathrm{L}$ of 3.3 $\mathrm{M}$ sodium methoxide (methanol solution) was added to the reaction mixture and the sample was homogenized. After $10 \mathrm{~min}$ incubation at r.t., the reaction was stopped with $30 \mu \mathrm{L}$ of acetic acid.

2.5. GC-MS Analysis. The organic phases containing FAMEs were injected $(0.5 \mu \mathrm{L})$ into a GC apparatus (HP5890 Series II, Agilent, Waldbronn, Germany) equipped with the column $(100 \mathrm{~m} \times 0.25 \mathrm{~mm}, 0.25 \mu \mathrm{m}) \mathrm{CP}-$ Select FAME (Varian, Palo Alto, CA, USA). The injector was kept at $270^{\circ} \mathrm{C}$. To determine the whole profile of FAs, the oven temperature ramped from $135^{\circ} \mathrm{C}$ to $250^{\circ} \mathrm{C}\left(2.5^{\circ} \mathrm{C} / \mathrm{min}\right)$ and was maintained at $250^{\circ} \mathrm{C}$ for $23 \mathrm{~min}$. The same program was followed, starting from $160^{\circ} \mathrm{C}$, when only LA and CLA had to be determined. Elution was performed with high-purity helium, with constant column head pressure of $200 \mathrm{kPa}$. Qualitative analyses of FAMEs were performed with a MS quadrupole detector (HP5972, Agilent). Analytes were identified by comparison with standards (O5632, Sigma Aldrich) and by analysis of their fragmentation patterns (EI, $70 \mathrm{eV}$ ) with the mass spectrum library NIST 2005 (Gatesburg, USA). Quantitative analyses were performed with a flame ionization detector held at $300^{\circ} \mathrm{C}$.

2.6. Alignment Analysis of Putative Bifidobacterium MCRA Genes and PCR Amplification. In order to verify the presence of homologues of MCRA from B. breve NCIMB 702258 (Protein ID ADY18551.1) a search was performed among all the species of Bifidobacterium, using the tblastn program provided by the National Center of Biotechnology Information (http://www.ncbi.nlm.nih.gov/). The available sequences of putative MCRA gene of Bifidobacterium spp. were aligned using the Clustal omega program (http://www.ebi.ac .uk/). To amplify the conserved region of MCRA genes, the primers MCRAf $\left(5^{\prime}\right.$-GCGGSCGCGARATGGACAA- $\left.3^{\prime}\right)$ and MCRAr ( $5^{\prime}$-CCGCCGTTGGTGATGAACAC- $\left.3^{\prime}\right)$ were designed. These primers anneal with the gene sequence of B. breve NCIMB 702258 (GenBank accession HQ593838H) at positions 236-255 and 958-978 and generate amplicons of $742 \mathrm{bp}$. Amplification was performed with the following program: $4 \mathrm{~min}$ at $94^{\circ} \mathrm{C} ; 30$ cycles of $30 \mathrm{~s}$ at $94^{\circ} \mathrm{C} ; 30 \mathrm{~s}$ at $58^{\circ} \mathrm{C}$; $1 \mathrm{~min}$ at $72^{\circ} \mathrm{C} ; 1 \mathrm{~min}$ at $72^{\circ} \mathrm{C}$.

2.7. Statistical Analysis. All values are described by the means and the standard deviation of three separate experiments. Comparisons were performed with one-way ANOVA followed by Tukey post hoc comparisons. Differences were considered statistically significant for $P<0.05$. Statistical analysis was done using GraphPad Prism 4.0 (GraphPad Software, San Diego, CA, USA). 


\section{Results}

3.1. Spectrophotometric Screening of Conjugated Linoleic Acid Production. 127 Bifidobacterium strains belonging to 31 different species or subspecies (Table 1) were cultured in MRSLA medium, containing $0.5 \mathrm{~g} / \mathrm{L}$ of free LA. With the exception of 3 strains belonging to the species $B$. coryneforme, $B$. gallinarum, and $B$. saeculare, unable to grow in presence of LA, all bifidobacteria grew in MRS-LA achieving $\mathrm{OD}_{600}$ ranging between 1.1 and 5.7 after $24 \mathrm{~h}$ (data not shown).

To obtain a preliminary estimation of CLA production, the supernatant of $24 \mathrm{~h}$ cultures in MRS-LA was extracted, and the UV absorbance by conjugated double bonds was measured at $\lambda=233 \mathrm{~nm}\left(A_{233}\right) . A_{233}$ ranged between 0 and 2.37 a.u., with the vast majority of the strains ( $>75 \%)$ yielding an extract with absorbance lower than 0.5 a.u. With the aim to validate the spectrophotometric assay, total CLA were quantified by GC-MS in the supernatant of 34 strains belonging to the species $B$. animalis subsp. lactis, B. bifidum, B. breve, $B$. catenulatum, $B$. longum subsp. infantis, B. longum subsp. longum, and $B$. pseudocatenulatum, covering the whole $A_{233}$ range. The dot dispersion of $A_{233}$ against CLA production revealed that CLA production can be excluded for $A_{233}<0.5$ (Figure 1(a)). Above this value, higher absorbance roughly corresponded to higher CLA concentration, although a direct relationship could not be established $\left(R^{2}=0.87\right)$.

All the strains belonging to the species $B$. adolescentis, B. angulatum, B. bifidum, B. boum, B. choerinum, B. cuniculi, $B$. dentium, B. gallicum, $B$. indicum, B. magnum, $B$. merycicum, B. minimum, B. pullorum, B. pseudolongum, B. psychraerophylum, B. ruminantium, B. scardovii, B. subtile, and $B$. thermophilum and most of the strains belonging to $B$. animalis subsp. animalis, B. animalis subsp. lactis, B. longum subsp. infantis, B. longum subsp. longum, and B. longum subsp. suis fell into the group of CLA producers (Figure 1(b)).

The species $B$. breve and the group of $B$. catenulatum and $B$. pseudocatenulatum were the highest CLA producers, even though wide variability was observed. The extracts of $B$. breve presented the highest $A_{233}$ (mean $=1.08$, median $=0.73$ ), followed by those of $B$. catenulatum and B. pseudocatenulatum (mean $=0.62$, median $=0.45$ ). All the strains with $A_{233}$ higher than the 90th percentile belonged to the species $B$. breve and B. pseudocatenulatum (Figure 1(b)). In particular, one strain of $B$. pseudocatenulatum and five of $B$. breve presented $A_{233}$ higher than 2.0 a.u. and were selected for deeper investigation of CLA production.

3.2. Search of MCRA Gene in Bifidobacterium Species. A tblastn search was performed for all the species of Bifidobacterium reported in Table 1 , in order to verify the presence of a homologue of MCRA from B. breve NCIMB 702258 (Protein ID ADY18551.1). Of the 31 species, 14 bear a gene encoding a protein with sequence identity from 55 to $94 \%$ : $B$. adolescentis, $B$. angulatum, B. animalis subsp. animalis, $B$. animalis subsp. lactis, $B$. bifidum, B. breve, B. catenulatum, $B$. dentium, $B$. longum subsp. infantis, B. longum subsp. longum, B. pseudocatenulatum, B. pseudolongum, B. scardovii, and B. thermophilum. All the 34 strains that were selected for the GC

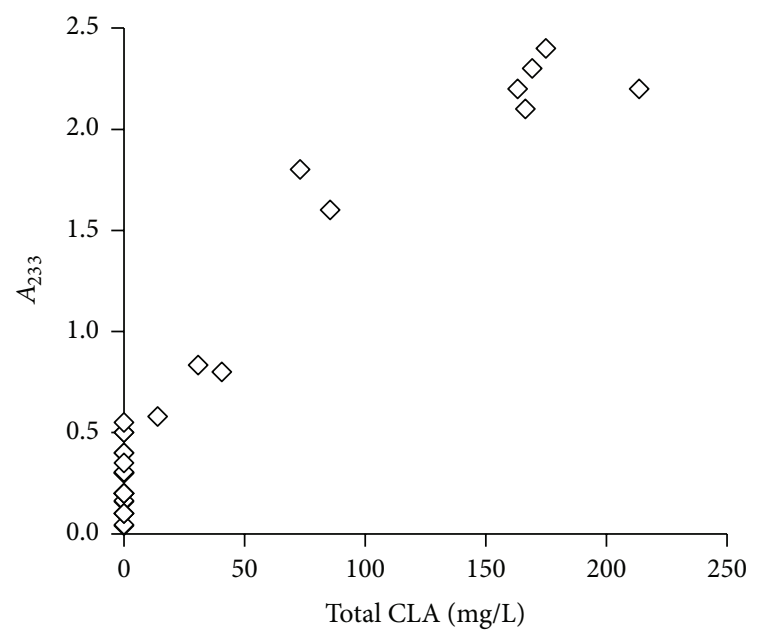

(a)

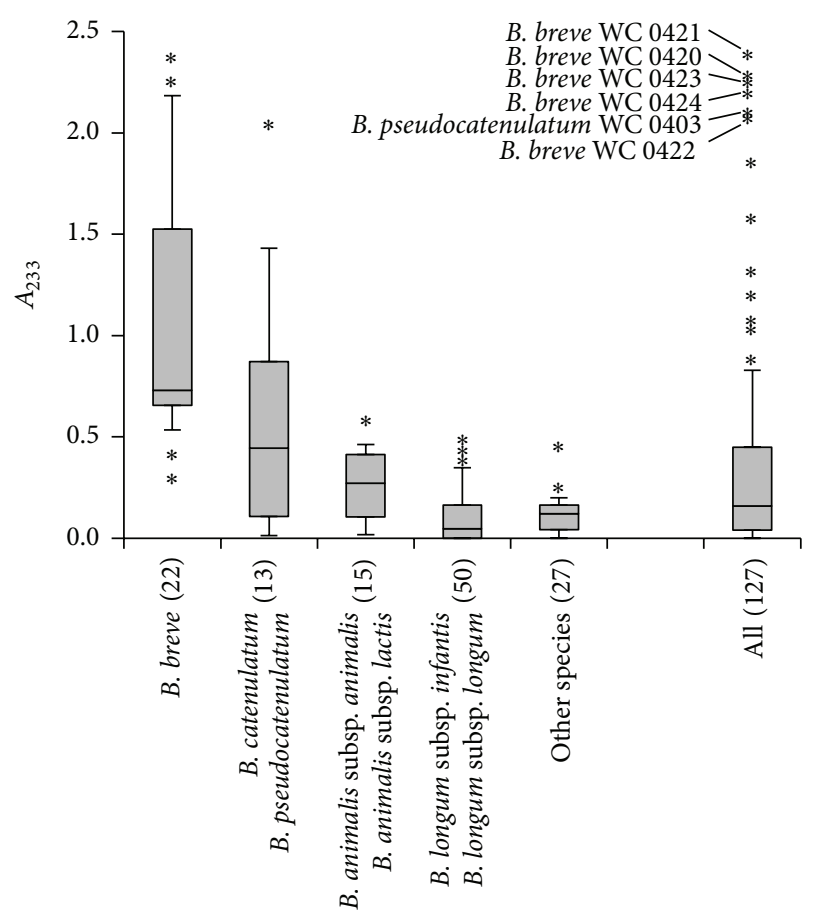

(b)

FIgURE 1: UV absorbance $\left(A_{233}\right)$ of the lipophilic extracts that were obtained from the supernatants of $24 \mathrm{~h}$ MRS-LA cultures of bifidobacteria. (a) Relationship between $A_{233}$ and total CLA concentration in the supernatant in a selection of 34 strains. (b) Screening of 127 Bifidobacterium strains. Boxes represent the range between 25th and 75th percentiles and the line inside represents the median. Whiskers denote the range between 10th and 90th percentiles and asterisks represent outlier values. Strains numbers are in brackets.

quantification of CLA were positive to MCRA-targeted PCR, yielding an amplicon of approx. $750 \mathrm{bp}$ (Table 1).

3.3. CLA Production by Selected Strains. Yields and the composition of CLA were determined in the supernatants of B. breve WC 0420, B. pseudocatenulatum WC 0403, B. 
TABLE 2: Residual LA (\%) and conversion yield into 9cis,11trans-CLA, 9trans,11trans-CLA, and total CLA (\%) by bifidobacteria cultured for $48 \mathrm{~h}$ in MRS-LA medium.

\begin{tabular}{|c|c|c|c|c|}
\hline & LA & 9cis,11trans-CLA & 9trans,11trans-CLA & Total CLA \\
\hline B. breve WC 0420 & $86.8^{\mathrm{a}}$ & $13.2^{\mathrm{a}}$ & $0.0^{\mathrm{a}}$ & $13.2^{\mathrm{a}}$ \\
\hline B. pseudocatenulatum WC 0403 & $81.5^{\mathrm{a}}$ & $14.3^{\mathrm{a}}$ & $4.2^{\mathrm{b}}$ & $18.5^{\mathrm{b}}$ \\
\hline B. breve WC 0422 & $58.2^{\mathrm{b}}$ & $37.2^{\mathrm{b}}$ & $4.7^{\mathrm{b}}$ & $41.8^{\mathrm{c}}$ \\
\hline B. breve WC 0424 & $22.7^{\mathrm{c}}$ & $70.2^{\mathrm{c}}$ & $7.0^{\mathrm{c}}$ & $77.3^{\mathrm{d}}$ \\
\hline B. breve WC 0423 & $12.4^{\mathrm{d}}$ & $80.3^{\mathrm{d}}$ & $7.3^{\mathrm{c}}$ & $87.6^{\mathrm{e}}$ \\
\hline B. breve WC 0421 & $11.9^{\mathrm{d}}$ & $81.1^{\mathrm{d}}$ & $7.0^{\mathrm{c}}$ & $88.1^{\mathrm{e}}$ \\
\hline
\end{tabular}

Values are means, $n=3$; SD always $<5 \%$. Means in a column with different superscripts significantly differ $(P<0.05)$.

breve WC 0422, B. breve WC 0424, B. breve WC 0423 , and B. breve WC 0421 , after $48 \mathrm{~h}$ of growth in MRS-LA (Table 2). Conversion of LA into CLA ranged between 13.2 and $88.1 \%$. B. breve WC 0421 and $B$. breve WC 0423 were the most efficient CLA producers, with yields of 88.1 and $87.6 \%$, respectively. 9cis,11trans-CLA and 9trans,11trans-CLA were the sole CLA isomers occurring in supernatants. The former was the major product of LA isomerization, accounting for 13.2 to $81.1 \%$ of LA conversion and for 77 to $100 \%$ of total CLA isomers. The latter was generally found in lower amount, never exceeding the $7.3 \%$ of LA conversion and the $23 \%$ of total CLA. The ratio 9cis,11trans-CLA:9trans,11trans-CLA ranged between 3.4 and 11.6 and increased augmenting the total amount of CLA produced. None of these strains produced hydroxylated forms of LA.

3.4. Kinetic of LA Isomerization into CLA by B. breve WC 0421. Constant-pH batch cultures of $B$. breve WC 0421 were carried out in MRS and MRS-LA. The presence of $0.5 \mathrm{~g} / \mathrm{L}$ LA caused an extension of the lag-phase of approx. $6 \mathrm{~h}$, slowed down the specific growth rate $\left(0.33\right.$ and $0.11 \mathrm{~h}^{-1}$ in MRS and MRS-LA, resp.), and delayed the entrance into stationary phase of $2 \mathrm{~h}$. The biomass/glucose yield was lower in MRS-LA than in MRS (8 and 13\%, resp.), whereas the percentage lipid/biomass was higher in the medium containing LA (7.5\% and $2.5 \%$, resp.). The isomerization of LA into CLA occurred mostly during the lag and the exponential phases (Figure 2). After $24 \mathrm{~h}$ of fermentation, during the exponential phase, the transformation of LA resulted in the production of 9 cis,11trans-CLA (83.6\%) and, at a minor extent, of trans9,trans11-CLA (4.5\%). During the late exponential and stationary phases, LA isomerization proceeded slowly and 9trans,11trans-CLA progressively accumulated at the expenses of 9 cis,11trans-CLA. Altogether, the conversion yield of LA into CLA was $94.3 \%$ after $52 \mathrm{~h}$. In particular, conversion yields into 9cis,11trans-CLA and 9trans,11trans-CLA were 68.8 and $25.1 \%$, respectively. All other CLA isomers were always negligible throughout the fermentation.

When $0.5 \mathrm{~g} / \mathrm{L}$ LA was added to MRS cultures at the entrance into the stationary phase, the isomerization occurred at minor extent, resulting in production of the sole 9 cis,11trans-CLA isomer with a conversion of $6.1 \%$ after $48 \mathrm{~h}$ incubation.

3.5. Lipid Composition of the Biomass. The profile of free and esterified fatty acids (FFA and EFA) within the lipid fraction

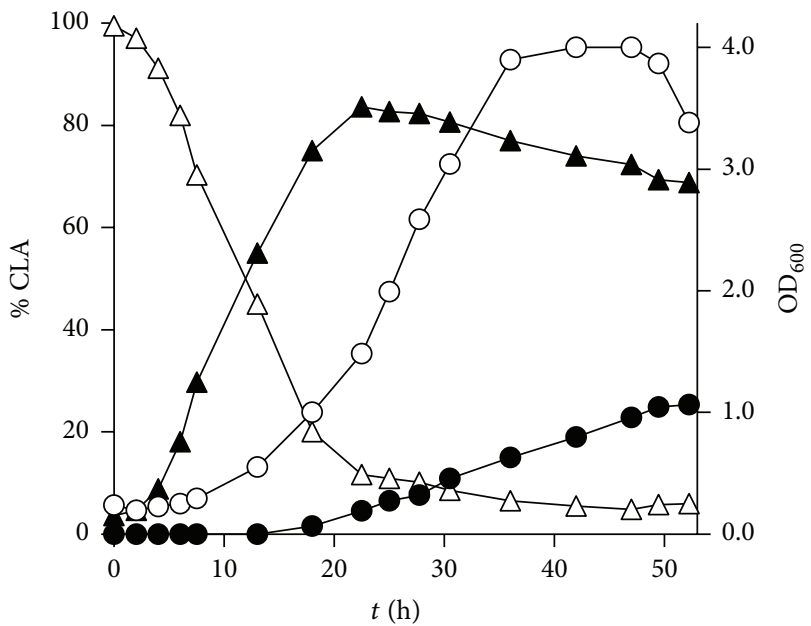

FIgURE 2: Time-course of growth and CLA production by $B$. breve WC 0421 in MRS medium containing $0.5 \mathrm{~g} / \mathrm{L}$ LA. $\bigcirc$ : turbidity $\left(\mathrm{OD}_{600}\right), \triangle$ : LA (\%), $\mathbf{\Delta}: 9$ cis,11trans-CLA (\%), and ๑: trans9,trans11CLA (\%). The results are representative of the three independent experiments.

of B. breve WC 0421 biomass was investigated (Table 3). In MRS, lipids were dominated by EFA ( $c a 93 \%$ of total lipids), while FFA were found in low amounts $(\leq 8 \%)$. At the exponential and stationary phases, oleic acid was the most abundant among both EFA and FFA, occurring for more than $40 \%$. Palmitic and myristic acids and palmitic and stearic acids represented the other major fatty acids among EFA and FFA, respectively.

During the cultivation in MRS-LA, B. breve WC 0421 accumulated a high amount of FFA, which accounted for $c a$ $75 \%$ of total lipids at the stationary phase. LA occurred in low amount $(<4 \%)$ among both EFA and FFA. 9cis,11trans-CLA dominated the profile of FFA, always accounting for more than $56 \%$. The composition of EFA was similar in MRS and MRS-LA.

The supplementation of $0.5 \mathrm{~g} / \mathrm{L}$ LA at the entrance into the stationary phase did not cause accumulation of relevant amounts of CLA as free or esterified fatty acid in the microbial biomass. $24 \mathrm{~h}$ after LA addition, EFA composition remained unchanged, while FFA increased up to $70 \%$ of the lipid extract. In this case, FFA were mostly composed of LA (77\%), whereas CLA altogether accounted for $c a 4 \%$. 
TABLE 3: Relative composition (\%) of esterified and free fatty acids (EFAs and FFAs, resp.) in the biomass of B. breve WC 0421 at the exponential and the stationary phase in MRS and MRS-LA.

\begin{tabular}{|c|c|c|c|c|c|c|}
\hline & & & \multicolumn{2}{|c|}{ MRS } & \multicolumn{2}{|c|}{ MRS-LA } \\
\hline & & & Exponential & Stationary & Exponential & Stationary \\
\hline \multirow{14}{*}{ EFA } & \multicolumn{2}{|c|}{ EFA/total FA } & $93^{\mathrm{a}}$ & $92^{\mathrm{a}}$ & $26^{\mathrm{b}}$ & $25^{\mathrm{b}}$ \\
\hline & $\mathrm{C} 10$ & & $0.8^{\mathrm{a}}$ & $1.7^{\mathrm{b}}$ & $1.2^{\mathrm{a}}$ & $1.7^{\mathrm{b}}$ \\
\hline & $\mathrm{C} 12$ & & $2.8^{\mathrm{a}}$ & $4.2^{\mathrm{b}}$ & $3.9^{\mathrm{b}}$ & $4.2^{\mathrm{b}}$ \\
\hline & $\mathrm{C} 14$ & & $8.6^{\mathrm{a}}$ & $16.6^{\mathrm{b}}$ & $13.7^{\mathrm{b}}$ & $15.7^{\mathrm{b}}$ \\
\hline & $\mathrm{C} 16$ & & 17.4 & 21.5 & 18.9 & 22 \\
\hline & $\mathrm{C} 16: 1$ & & 1.1 & 1.9 & 1.9 & 2 \\
\hline & $\mathrm{C} 17$ & & 0.9 & 0.5 & 0 & 0.4 \\
\hline & $\mathrm{C} 18$ & & $4.2^{\mathrm{a}}$ & $3.1^{\mathrm{a}}$ & $0.0^{\mathrm{b}}$ & $1.7^{\mathrm{b}}$ \\
\hline & $\mathrm{C} 18: 1$ & & $55.8^{\mathrm{a}}$ & $41.3^{\mathrm{b}}$ & $50.9^{\mathrm{a}}$ & $43.9^{\mathrm{b}}$ \\
\hline & $\mathrm{C} 18: 2$ & LA & 2.1 & 3.2 & 3.7 & 3.1 \\
\hline & $\mathrm{C} 18: 2$ & 9cis,11trans-CLA & 1.6 & 1.2 & 0.9 & 1 \\
\hline & $\mathrm{C} 18: 2$ & 9trans,11trans-CLA & 3.6 & 3.9 & 5 & 4 \\
\hline & $\mathrm{C} 20$ & & 0.3 & 0.3 & 0 & 0.1 \\
\hline & $\mathrm{C} 22$ & & 0.8 & 0.5 & 0 & 0.4 \\
\hline \multirow{14}{*}{ FFA } & \multicolumn{2}{|c|}{ FFA/total FA } & $7^{\mathrm{a}}$ & $8^{\mathrm{a}}$ & $74^{\mathrm{b}}$ & $75^{\mathrm{b}}$ \\
\hline & $\mathrm{C} 10$ & & 0 & 0 & 0 & 0 \\
\hline & $\mathrm{C} 12$ & & 0 & 0 & 0 & 0 \\
\hline & $\mathrm{C} 14$ & & $3.2^{\mathrm{a}}$ & $12.7^{\mathrm{b}}$ & $1.2^{\mathrm{a}}$ & $0.6^{\mathrm{a}}$ \\
\hline & $\mathrm{C} 16$ & & $23.6^{\mathrm{a}}$ & $22.0^{\mathrm{a}}$ & $5.7^{\mathrm{b}}$ & $2.4^{\mathrm{b}}$ \\
\hline & $\mathrm{C} 16: 1$ & & 0 & 0 & 0 & 0 \\
\hline & $\mathrm{C} 17$ & & $3.1^{\mathrm{a}}$ & $1.6^{\mathrm{a}}$ & $0.6^{\mathrm{b}}$ & $0.3^{\mathrm{b}}$ \\
\hline & $\mathrm{C} 18$ & & $10.4^{\mathrm{a}}$ & $6.8^{\mathrm{a}}$ & $2.5^{\mathrm{b}}$ & $1.2^{\mathrm{b}}$ \\
\hline & $\mathrm{C} 18: 1$ & & $47.0^{\mathrm{a}}$ & $46.2^{\mathrm{a}}$ & $13.9^{\mathrm{b}}$ & $8.3^{\mathrm{b}}$ \\
\hline & $\mathrm{C} 18: 2$ & LA & $0.0^{\mathrm{a}}$ & $0.0^{\mathrm{a}}$ & $1.7^{\mathrm{b}}$ & $2.8^{\mathrm{b}}$ \\
\hline & $\mathrm{C} 18: 2$ & 9cis,11trans-CLA & $2.1^{\mathrm{a}}$ & $2.7^{\mathrm{a}}$ & $58.6^{\mathrm{b}}$ & $56.6^{\mathrm{b}}$ \\
\hline & $\mathrm{C} 18: 2$ & 9trans,11trans-CLA & $3.3^{\mathrm{a}}$ & $7.1^{\mathrm{a}}$ & $15.2^{\mathrm{b}}$ & $27.0^{\mathrm{c}}$ \\
\hline & $\mathrm{C} 20$ & & 4 & 0.9 & 0.2 & 0.4 \\
\hline & $\mathrm{C} 22$ & & 3.2 & 0 & 0.5 & 0.3 \\
\hline
\end{tabular}

Values are means, $n=3$; SD always $<5 \%$. Means in a row with different superscripts significantly differ $(P<0.05)$.

\section{Discussion}

The present study aims to gain further insight into CLA production by bifidobacteria, since the capability of certain strains to convert LA into CLA could find application in the development of specific probiotic strains able to accelerate or improve in vivo conversion of LA into CLA.

In vivo studies supporting biological activity of CLA were initially performed using a mixture of CLA isomers, while purified isomers have been used more recently, supporting the evidence that different isomers have distinct effect on the major health targets, such as tumorigenesis and lipid metabolism [1]. However, most of commercial formulations of CLA still contain both major isomers, whose biological activity is mediated by diverse signaling pathways. 9cis,11trans-CLA isomer exerts an enhancing effect on the nuclear transmission of $\operatorname{PPAR} \gamma$, a master regulator of adipocyte differentiation, acting as a stimulator of adiponectin secretion [17]. This mechanism can to some extent explain the antihypertensive, antihyperlipidemic, antiarteriosclerotic, anticarcinogenic, and antidiabetic effects mediated by this CLA [18]. Conversely, trans10,cis12-CLA increases lipolysis and has the function of diminishing the synthesis of fatty acids [19] but also presents a linkage with proatherogenic effects, insulin resistance, and inflammation [20].

The perspective to exploit specifically selected probiotic bifidobacteria to produce a definite CLA isomer, such as the 9cis,11trans-CLA, is quite attractive. The data herein presented demonstrate that selected strains of bifidobacteria specifically convert linoleic acid (LA) into 9cis,11trans-CLA isomer, whereas 10 trans, 12 cis-CLA, for which potential harmful biological activities are still debated, is not produced by the tested strains.

The screening of CLA production among the major species of bifidobacteria demonstrated that the most efficient CLA producers belong to the species $B$. breve and $B$. pseudocatenulatum. Consistently, $B$. breve strains have been 
previously identified among the best CLA producers, whereas low or negligible activity was found in the strains belonging to $B$. adolescentis, $B$. angulatum, $B$. bifidum, and $B$. infantis $[2,9,21]$. Unlike previous studies that indicated B. pseudocatenulatum as almost incapable of LA transformation [2], our data revealed that some strains of B. pseudocatenulatum can efficiently accomplish the isomerization of LA.

The data herein presented are in agreement with observations by O'Connell et al. [9], which excluded that the product of MCRA gene is involved in LA isomerization to CLA. In the present study, all the best producers of CLA, belonging to the species $B$. breve and $B$. pseudocatenulatum, were positive to this gene, yet no hydroxylated forms of LA were detected in their supernatants or in the biomass of $B$. breve WC 0421. A further clue hinting that MCRA is not involved in CLA production is the fact that both MCRA-targeted PCR and BLAST search for the gene revealed the presence of a homologue in CLA producer and nonproducer species.

B. breve WC 0421 emerged as the most promising strain for production of 9 cis,11trans-CLA isomer. Our results associate the production of cis9,trans11-CLA to the lag and early growth phases, whereas supplementation of LA into stationary phases resulted in negligible production of CLA. This result supports the hypothesis that transformation of LA in CLA can be a strategy of bacteria to detoxify unsaturated fatty acid that interfere with membrane lipids. These in vitro experiments have been carried out in batch, with a pure culture, on a rich medium, with condition very different from the intestinal ecosystem, where bifidobacteria represent only a few percent of a complex mixed population. However, bioproduction of CLA by supplemental probiotic bifidobacteria has been previously demonstrated [10]. For this reason, $B$. breve WC 0421 may represent a promising candidate for in vivo production of the specific health-promoting CLA isomer.

The attention of the scientific community has been focused on CLA production and absorption in the gastrointestinal tract. The analysis of fatty acid profile of biomass associated lipids revealed that when $B$. breve WC 0421 was cultured in presence of LA it accumulated CLA in the form of free fatty acids, without changing the composition of its esterified fatty acids, mainly occurring in the plasmatic membrane.

\section{Conclusions}

Bifidobacteria are one of the most relevant health-promoting indigenous species of the human gut microbiota, exerting beneficial positive effects through a variety of different mechanisms. Our study strengthened the perspectives on a more specific use of probiotics, where the intrinsic healthpromoting properties of bifidobacteria can be associated with peculiar features, such as producing in vivo health-promoting CLA. Based on the current knowledge $[2,9,21]$ and on the outcome of this study, selected strains of Bifidobacterium, mostly belonging to the species $B$. breve, can be exploited as probiotics for in vivo production of 9 cis,11trans-CLA.

The assessment of production and incorporation of CLA in bifidobacterial biomass is a relevant result of our study.
Since the host-bacteria interaction is mediated by several surface compounds, it is necessary to investigate the location of 9cis,11trans-CLA within bifidobacterial cells and to examine whether CLA enriched bifidobacteria exert a diverse biological effect than the corresponding CLA-free cells.

\section{Competing Interests}

The authors declare that they have no competing interests.

\section{Authors' Contributions}

Stefano Raimondi and Alberto Amaretti contributed equally to this work.

\section{References}

[1] J. H. Kim, Y. Kim, Y. J. Kim, and Y. Park, "Conjugated linoleic acid: potential health benefits as a functional food ingredient," Annual Review of Food Science and Technology, vol. 7, no. 1, pp. 221-244, 2016.

[2] M. Coakley, R. P. Ross, M. Nordgren, G. Fitzgerald, R. Devery, and C. Stanton, "Conjugated linoleic acid biosynthesis by human-derived Bifidobacterium species," Journal of Applied Microbiology, vol. 94, no. 1, pp. 138-145, 2003.

[3] E. Devillard, F. M. McIntosh, S. H. Duncan, and R. J. Wallace, "Metabolism of linoleic acid by human gut bacteria: different routes for biosynthesis of conjugated linoleic acid," Journal of Bacteriology, vol. 189, no. 6, pp. 2566-2570, 2007.

[4] F. M. McIntosh, K. J. Shingfield, E. Devillard, W. R. Russell, and R. J. Wallace, "Mechanism of conjugated linoleic acid and vaccenic acid formation in human faecal suspensions and pure cultures of intestinal bacteria," Microbiology, vol. 155, no. 1, pp. 285-294, 2009.

[5] H. C. Soo, H. K. In, G. P. Hui et al., "Synthesis of conjugated linoleic acid by human-derived Bifidobacterium breve LMC 017: utilization as a functional starter culture for milk fermentation," Journal of Agricultural and Food Chemistry, vol. 56, no. 9, pp. 3311-3316, 2008.

[6] A. O. Edionwe and C. Kies, "Comparison of palm and mixtures of refined palm and soybean oils on serum lipids and fecal fat and fatty acid excretions of adult humans," Plant Foods for Human Nutrition, vol. 56, no. 2, pp. 157-165, 2001.

[7] A. Volkov, A. Liavonchanka, O. Kamneva et al., "Myosin crossreactive antigen of Streptococcus pyogenes M49 encodes a fatty acid double bond hydratase that plays a role in oleic acid detoxification and bacterial virulence," The Journal of Biological Chemistry, vol. 285, no. 14, pp. 10353-10361, 2010.

[8] E. Rosberg-Cody, A. Liavonchanka, C. Göbel et al., "Myosincross-reactive antigen (MCRA) protein from Bifidobacterium breve is a FAD-dependent fatty acid hydratase which has a function in stress protection," BMC Biochemistry, vol. 12, article 9, 2011.

[9] K. J. O'Connell, M. O. Motherway, A. A. Hennessey et al., "Identification and characterization of an oleate hydrataseencoding gene from Bifidobacterium breve," Bioengineered, vol. 4, no. 5, pp. 313-321, 2013.

[10] J. B. Ewaschuk, J. W. Walker, H. Diaz, and K. L. Madsen, "Bioproduction of conjugated linoleic acid by probiotic bacteria occurs in vitro and in vivo in mice," Journal of Nutrition, vol. 136, no. 6, pp. 1483-1487, 2006. 
[11] M. Rossi, A. Amaretti, A. Leonardi, S. Raimondi, M. Simone, and A. Quartieri, "Potential impact of probiotic consumption on the bioactivity of dietary phytochemicals," Journal of Agricultural and Food Chemistry, vol. 61, no. 40, pp. 9551-9558, 2013.

[12] M. Rossi and A. Amaretti, "Probiotic properties of bifidobacteria," in Bifidobacteria-Genomics and Molecular Aspects, B. Mayo and D. van Sinderen, Eds., pp. 97-123, Caiser Academic Press, Norfolk, UK, 2010.

[13] N. T. Williams, "Probiotics," American Journal of Health-System Pharmacy, vol. 67, no. 6, pp. 449-458, 2010.

[14] E. Barrett, R. P. Ross, G. F. Fitzgerald, and C. Stanton, "Rapid screening method for analyzing the conjugated linoleic acid production capabilities of bacterial cultures," Applied and Environmental Microbiology, vol. 73, no. 7, pp. 2333-2337, 2007.

[15] W. W. Christie, "Preparation of ester derivatives of fatty acids for chromatographic analysis," in Advances in Lipid MethodologyTwo, W. W. Christie, Ed., pp. 69-111, Oily Press, Dundee, UK, 1993.

[16] S. Raimondi, M. Rossi, A. Leonardi, M. M. Bianchi, T. Rinaldi, and A. Amaretti, "Getting lipids from glycerol: new perspectives on biotechnological exploitation of Candida freyschussii," Microbial Cell Factories, vol. 13, no. 1, article 83, 2014.

[17] G. Yuan, X. Chen, and D. Li, "Modulation of peroxisome proliferator-activated receptor gamma (PPAR $\gamma$ ) by conjugated fatty acid in obesity and inflammatory bowel disease," Journal of Agricultural and Food Chemistry, vol. 63, no. 7, pp. 1883-1895, 2015.

[18] G.-F. Yuan, X.-E. Chen, and D. Li, "Conjugated linolenic acids and their bioactivities: a review," Food and Function, vol. 5, no. 7, pp. 1360-1368, 2014.

[19] S. V. Martins, A. Madeira, P. A. Lopes et al., "Adipocyte membrane glycerol permeability is involved in the anti-adipogenic effect of conjugated linoleic acid," Biochemical and Biophysical Research Communications, vol. 458, no. 2, pp. 356-361, 2015.

[20] T. E. Lehnen, M. R. da Silva, A. Camacho, A. Marcadenti, and A. M. Lehnen, "A review on effects of conjugated linoleic fatty acid (CLA) upon body composition and energetic metabolism," Journal of the International Society of Sports Nutrition, vol. 12, no. 1, article 36, 2015.

[21] S. H. Chung, I. H. Kim, H. G. Park et al., "Synthesis of conjugated linoleic acid by human-derived Bifidobacterium breve LMC 017: utilization as a functional starter culture for milk fermentation," Journal of Agricultural and Food Chemistry, vol. 56, no. 9, pp. 3311-3316, 2008. 

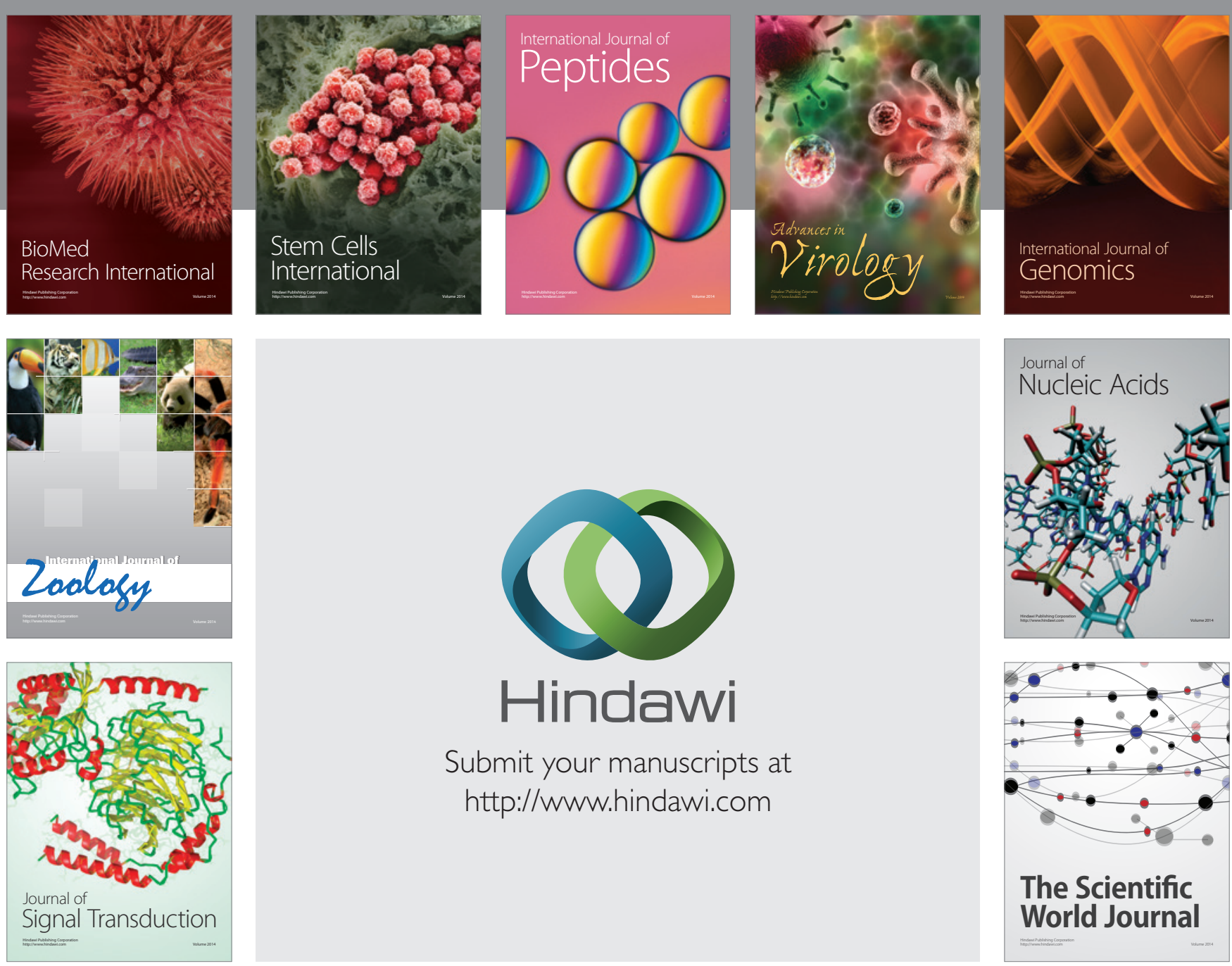

Submit your manuscripts at

http://www.hindawi.com
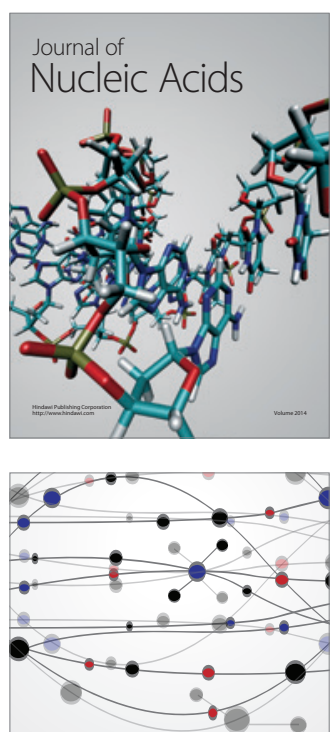

The Scientific World Journal
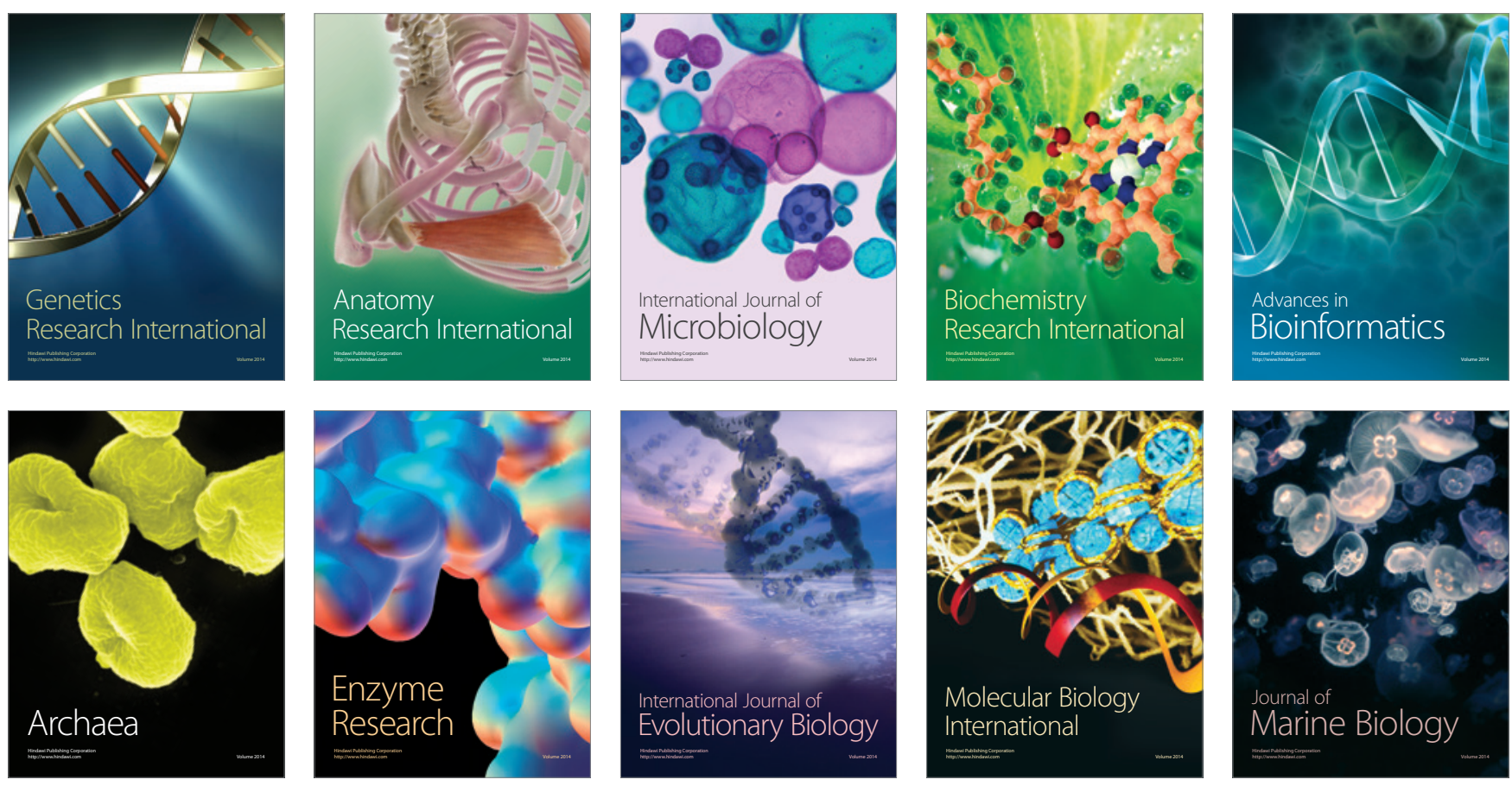